\title{
Effect of placental sex hormone-binding globulin single nucleotide polymorphism rs6259 on protein and function in gestational diabetes mellitus
}

\author{
XUAN ZHANG* , LEI SUN* ${ }^{*}$ and ZHEN JIN \\ Department of Obstetrics and Gynecology, Shengjing Hospital Affiliated to \\ China Medical University, Shenyang, Liaoning 110000, P.R. China \\ Received November 10, 2016; Accepted February 9, 2018
}

DOI: $10.3892 /$ ijmm.2018.3503

\begin{abstract}
Sex hormone-binding globulin (SHBG) has a key role in the occurrence and development of the gestational diabetes mellitus (GDM). Single nucleotide polymorphism (SNP) rs6259 is a functional site in SHBG gene, which is suspected to regulate the SHBG level. The present study explored the placental SHBG SNP rs6259 distribution in Chinese pregnant women and the influence on placental SHBG concentrations, to assess the relationship of SHBG rs6259 in the occurrence and development of GDM. We screened the SHBG rs6259 allele in 210 healthy and 180 GDM gravidas by PCR-RFLP and restriction enzyme and measured placental SHBG concentrations in each genotypic group with western blot analysis. The mechanisms of SHBG rs6259 function were analyzed by cell culture, recombinant lentivirus transfection, real-time PCR, and western blot analysis. We found the differences of SHBG Asn $^{327}$ allele frequency and the genotype distribution in GDM and control groups were statistically significant $(\mathrm{P}<0.05)$. Western blot analysis results showed that the $\mathrm{Asn}^{327}$ allele group was associated with a higher placental SHBG level than the $\mathrm{Asp}^{327}$ allele homozygote group $(\mathrm{P}<0.05)$. In HTR8SVneo cell transfection, the positive transfection groups (SHBG-rs6259 Asn) led to an obviously higher tendency of SHBG mRNA and protein expression than the negative control groups (SHBG-rs6259 Asp), the normal cell group, and the blank control group (blank lentivirus LV-5) $(\mathrm{P}<0.05)$. Our data, therefore, reflected that SHBG SNP rs6259 causes changes in
\end{abstract}

Correspondence to: Professor Zhen Jin or Professor Lei Sun, Department of Obstetrics and Gynecology, Shengjing Hospital Affiliated to China Medical University, 36 Sanhao Street, Shenyang, Liaoning 110000, P.R. China

E-mail: jinzhen66@yahoo.com.cn

E-mail: fcksunlei@126.com

*Contributed equally

Key words: single nucleotide polymorphism, sex hormone-binding globulin, rs6259 (D327N, Asp $\left.{ }^{327} \mathrm{Asn}\right)$, mutation, trophoblast cell placental SHBG concentration and may play a functional role in the molecular mechanisms of GDM etiology.

\section{Introduction}

Gestational diabetes mellitus (GDM) is defined as abnormal or impaired glucose metabolism before pregnancy and it initially appears during pregnancy. GDM may lead to early embryo abnormalities or even death, pregnancy-induced hypertension syndrome, infection, polyhydramnios and premature labor. It will also affect the status of the fetus, including effects such as fetal malformation, macrosomia or stillbirth. The offspring of woman with GDM are more inclined to develop low blood sugar, respiratory distress syndrome and polycythemia. Furthermore, these offspring have a higher risk of developing obesity and impaired glucose tolerance and the mother with GDM is more likely to develop diabetes [mainly type 2 diabetes mellitus (DM)] later in life.

In recent years, the incidence of GDM has increased significantly. In China, the incidence of GDM has increased significantly and women with GDM account for 3-7\% of pregnancies (1). The pathophysiological basis of GDM world-wide includes increased insulin resistance and decreased secretion of $\beta$-cell during pregnancy $(2,3)$. Sex hormone-binding globulin (SHBG) is a glycoprotein produced in the liver, specifically to bind and transport sex hormones, and regulate the biological activity and the concentration of sex hormone in the blood (4). Previous studies have shown that the level of SHBG was decreased in women with insulin tolerance and GDM (5). A low SHBG level is an independent risk factor for type $2 \mathrm{DM}$, which has been suggested as a predictor for hyperinsulinemia and insulin tolerance (6). Higher SHBG concentrations can effectively prevent impaired fasting glucose, the occurrence of type $2 \mathrm{DM}$ and hyperinsulinemia (7).

Placenta is a combination of tissues of embryo and mother, carrying the exchange of substances. It consists of amniotic membrane, chorion frondosum and deciduas. Placenta is evolved from the fertilized egg and has the same genetic material with the fetus. Our prior experiments on the changes of SHBG in GDM placental tissue have been confirmed that SHGB can be synthesized and secreted by the 
placenta trophoblast cells, SHBG mRNA and SHBG protein concentration were significantly decreased in the GDM group $(\mathrm{P}<0.01)$, and that of SHBG played an important role in the occurrence and development of GDM (8-10).

The single-nucleotide polymorphism, rs6259, is a functioning gene mutation within a coding region of the SHBG gene. Nucleotide 5790 within exon 8 of the SHBG gene has a missense mutation (GAC $\rightarrow$ AAC), and the carboxyl-terminal globular laminin domain created a new $\mathrm{N}$-connecting carbohydrate chain, which could provide for an additional $\mathrm{N}$-glycosylation site $(11,12)$. Glycosylation does not affect the binding of steroids to SHBG, but it may decrease the plasma clearance of SHBG and prolong its half-life $(13,14)$. This substitution may lead to increased SHBG levels, changes in gene polymorphism (TAAAA)n and has influence on transcription of the non-coding region (11). Studies have confirmed that the increased SHBG levels in hirsutism (11) and polycystic ovary syndrome (3) are associated with the variant $\mathrm{Asn}^{327}$ allele. Ding et al (15) found that $\mathrm{Asn}^{327}$ allele carriers have higher SHBG levels in plasma (10\%) than $\mathrm{Asp}^{327}$ carriers $(\mathrm{P}=0.005)$. This single nucleotide polymorphism (SNP) rs6259 has different frequencies in ethnic groups around the world (13). In healthy Caucasians it was $7.5-12 \%$, in African Americans 2\%, and the highest frequency was found in Chinese women (16-21).

The present study focused on the distribution of the human SHBG SNP rs6259, its correlation with placental SHBG levels and the occurrence and development of GDM, to predict the risk of diabetes in the next generation.

\section{Patients and methods}

Patients and sample collection. All subjects were from Shengjing Hospital, which is affiliated with China Medical University. This study was approved by the Ethics Committee of Shengjing Hospital, and all participants provided informed consent.

In total, 180 women with singleton pregnancy, positive oral glucose tolerance test (OGTT), and regular prenatal examinations were selected into the study. The normal group was comprised of 210 cases that were OGTT negative, healthy pregnant women with singleton pregnancy over the same period. Pregnant women with a complication, such as gestational hypertension and pregestational DM were excluded. The GDM group was selected from the outpatients whose glucose was well-controlled and who received systematic examinations during the pregnancy from November 2012 to September 2014. According to the American Diabetes Association (22), the recommended GDM diagnosis is: i) fasting plasma glucose over $5.1 \mathrm{mmol} / \mathrm{l}$ during pregnancy; and ii) blood glucose levels at 1 and $2 \mathrm{~h}$ after taking 75 -g oral glucose over 10.0 and $8.5 \mathrm{mmol} / 1$ during gestational weeks 24 to 28 . Either one beyond the diagnostic boundary can be identified as GDM.

The placental tissues of the two groups were collected from each patient immediately after delivery. The tissue was cut into $\sim 0.5 \mathrm{~cm}^{3}$ pieces from placenta on the side of the mother, central and marginal areas. Cold normal saline was used to wash the pieces before they were dissected into small sections, which were blotted dry on filter paper and snap-frozen in liquid nitrogen for $4 \mathrm{~h}$, before being stored at $-80^{\circ} \mathrm{C}$.
Clinical index collection. We had statistics on general information in the selected 390 cases, including in pregnant women the age, gestational weeks, birth weight, childbearing history and fasting blood glucose, and the differences were compared between the two groups.

DNA sample preparation. Genomic DNA was extracted from placental samples by a blood/cell/tissue genomic DNA extraction kit (Tiangen Biotech Co., Ltd., Beijing, China) strictly according to the manufacturer's instructions. The test result determination must take the microtiter plate reader as a standard.

Polymerase chain reaction-restriction fragment length polymorphism (PCR-RFLP) and agarose gel electrophoresis. PCR primer sequences were as follows: forward primer, 5'-TTCTGGATCCGAGCCACCT-3' and reverse primer, 5'-AGTGCCTGGTACATTGCTAG-3' (Invitrogen Life Technologies, Carlsbad, CA, USA). Each PCR reaction contained, DNA template $2 \mu 1$, Takara Ex Taq $(5 \mathrm{U} / \mu 1)$ $0.25 \mu \mathrm{l}$, dNTP mixture $(2.5 \mathrm{mM}) 4 \mu \mathrm{l}, 1 \mu \mathrm{l}(10 \mu \mathrm{M})$ each of SHBG forward and reverse primers, 10X Ex Taq buffer ( $\mathrm{Mg}^{2+}$ Plus) $5 \mu \mathrm{l}$, with ultrapure water added to $50 \mu \mathrm{l}$ total volume (Takara Bio, Inc., Otsu, Japan). The PCR conditions: initial denaturation at $94^{\circ} \mathrm{C}$ for $5 \mathrm{~min}$. PCR profiles consisted of 35 cycles with denaturation at $94^{\circ} \mathrm{C}$ for $10 \mathrm{sec}$, annealing at $55^{\circ} \mathrm{C}$ for $30 \mathrm{sec}$, and extension at $72^{\circ} \mathrm{C}$ for $60 \mathrm{sec}$, followed by a final extension at $72^{\circ} \mathrm{C}$ for $7 \mathrm{~min}$. PCR products were electrophoresed in a $2 \%$ agarose gel and visualized by ethidium bromide and UV light (c150; Azure Biosystems, Inc., Dublin, CA, USA).

Restriction enzyme digestion technique. According to the SNP mutation site gene, we selected the restriction enzyme HinfI (Takara Bio, Inc.) for the treatment of PCR amplified fragments, to carry on the identification of the gene. All of the 180 GDM and 210 in the control group PCR amplified fragments were by HinfI. The reaction system contained Takara HinfI $1 \mu 1$, 10X HinfI buffer $2 \mu 1$, PCR template $7-8 \mu 1$, add ultrapure water to $20 \mu \mathrm{l}$, kept in $37^{\circ} \mathrm{C}$ water for $8 \mathrm{~h}$. The fragments digested by HinfI were electrophoresed in a $3 \%$ agarose gel. Genotypes were determined by the results of various bands though UV light (c150; Azure Biosystems, Inc.).

Western blot analysis and SDS-PAGE. Placental tissue total protein was extracted by RIPA with phenylmethylsulfonyl fluoride (PMSF) (Beyotime Institute of Biotechnology, Shanghai, China). Then put into homogenizer to grind into tissue homogenate and the supernatant was collected and centrifuged at $14,000 \mathrm{x} \mathrm{g}$ at $4^{\circ} \mathrm{C}$ for $5 \mathrm{~min}$. The protein concentration was quantified by BCA assay. Then, samples containing $50 \mu \mathrm{g}$ were separated by polyacrylamide gel electrophoresis with a $10 \%$ separating gel $(\mathrm{pH} 8.8)$ and a 5\% stacking gel ( $\mathrm{pH}$ 6.8) (Beyotime Institute of Biotechnology) and the proteins were transferred onto PVDF membranes (Millipore, Billerica, MA, USA). Membranes were incubated with primary antibody: goat anti-human SHBG polyclonal antibody (INC sc-32468, 1:2,000 dilution; Santa Cruz Biotechnology, Inc., Santa Cruz, CA, USA) and GAPDH monoclonal antibody (60004-1-1g, 1:10,000 dilution; Proteintech, Wuhan, China) overnight 
at $4^{\circ} \mathrm{C}$ after blocking in 5\% skim milk for $2 \mathrm{~h}$. Following three washes with $1 \mathrm{X}$ Tris-buffered saline containing $0.1 \%$ Tween-20 (TBST), the membranes were incubated in secondary antibody: HBP-conjugated rabbit anti-goat IgG (Ab-204-01, 1:5,000 dilution; Vazyme, Nanjing, China) and peroxidase-conjugated AffiniPure goat anti-mouse $\mathrm{IgG}$ (SA00001-1, 1:2,000 dilution; Proteintech) for $120 \mathrm{~min}$ then room temperature for $2 \mathrm{~h}$. Immune complexes were detected with enhanced chemiluminescence (ECL) (Beyotime Institute of Biotechnology). A bioanalytical imaging system (c300; Azure Biosystems, Inc.) was used to catch the bands. All experiments were repeated at least three times. Data were expressed as a ratio of SHBG gray value to GAPDH (ImageJ; National Institutes of Health, Bethesda, MA, USA).

Cell culture. The placenta villus trophoblast cells HTR8-SVneo were obtained from Canada Queen's University and cultured conventionally with RPMI-1640 medium, supplemented with $10 \%$ heat-inactivated fetal bovine serum (FBS) (Gibco, Carlsbad, CA, USA). Standard culture condition: $37^{\circ} \mathrm{C}$, $5 \%$ humidified $\mathrm{CO}_{2}$ incubator. Cell culture supplies were purchased from the Greiner Bio-One GmbH (Frickenhausen, Germany), trypsin (Gibco).

Transfection. The recombinant lentivirus was designed and synthesized with all of the SBHG genetic sequence labeled by green fluorescence (GenePharma, Shanghai, China). For this part, HTR8-SVneo cells were divided into ten flasks, some of which had upregulated SHBG expression. A and B were the normal groups (without transfection), $\mathrm{C}$ and $\mathrm{D}$ were the blank control groups (transfected with empty virus LV-5). E-G were negative control groups (respectively transfected with SHBG rs6259 Asp-1, rs6259 Asp-2 and rs6259 Asp-3). H-J were the positive transfection group (respectively transfected with SHBG rs6259 Asn-1, rs6259 Asn-2 and rs6259 Asn-3).

One day before transfection, cells were cultured with $90 \%$ RPMI-1640+10\% FBS and seeded in $25 \mathrm{~cm}^{2}$ flasks $\left(250-500 \times 10^{3}\right.$ cells/flasks), cultivated at $37^{\circ} \mathrm{C}$, in $5 \% \mathrm{CO}_{2}$ incubator. Twenty-four hours later, the cell growth reached $30-40 \%$, the medium was replaced and the cells were transfected with the lentivirus. Cells were incubated at $37^{\circ} \mathrm{C}$, morphological structure was observed at $12 \mathrm{~h}$ and the culture media was changed at $24 \mathrm{~h}$. After $96 \mathrm{~h}$, transfection efficiency was determined by using fluorescence imaging. Then, the cells were collected, SHBG mRNA and protein were assayed via western blot analysis and RT-qPCR.

Gene expression analysis by reverse transcription-quantitative polymerase chain reaction (RT-qPCR). Total SHBG mRNA was extracted by TRIzol reagent (Invitrogen Life Technologies) from transfected cells according to the manufacturer's instructions. Amplification of SHGB cDNA fragment was divided into two parts: i) removal of extraneous DNA contamination: $1 \mu 1 \mathrm{RNA}$ template, $2 \mu \mathrm{l} 5 \mathrm{X} \mathrm{g}$ DNA Erase buffer, $1 \mu 1 \mathrm{~g}$ DNA Erase buffer, $6 \mu 1$ RNase Free $\mathrm{dH}_{2} \mathrm{O}$, at $42^{\circ} \mathrm{C}$ for $2 \mathrm{~min}$, then for $4^{\circ} \mathrm{C}$; ii) cDNA production: $4 \mu 15 \mathrm{X}$ g Premix Script buffer 2, $1 \mu 1$ Premix Script RT enzyme mix, $1 \mu \mathrm{l}$ RT Primix Mix and $4 \mu \mathrm{l}$ RNase Free $\mathrm{dH}_{2} \mathrm{O}$ into reaction volume from step 1 , at $37^{\circ} \mathrm{C}$ for $15 \mathrm{~min}$, at $85^{\circ} \mathrm{C}$ for $5 \mathrm{sec}$, then for $4^{\circ} \mathrm{C}$ (no. RR047A; Takara Bio, Inc.).
Table I. Clinical characteristics of normal and GDM pregnant women.

\begin{tabular}{lccc}
\hline Characteristics & $\begin{array}{c}\text { GDM } \\
\text { group }\end{array}$ & $\begin{array}{c}\text { Control } \\
\text { group }\end{array}$ & P-value \\
\hline Numbers & 180 & 210 & \\
Age (years) & $31.59 \pm 3.89$ & $31.73 \pm 4.46$ & $0.735^{\mathrm{b}}$ \\
Fasting blood glucose & $5.04 \pm 0.86$ & $4.32 \pm 0.44$ & $0.000^{\mathrm{a}}$ \\
Gestational weeks & $38.69 \pm 1.13$ & $38.83 \pm 0.79$ & $0.141^{\mathrm{b}}$ \\
Childbearing history & $0.10 \pm 0.31$ & $0.16 \pm 0.37$ & $0.056^{\mathrm{b}}$ \\
Birth weight (g) & $3445.6 \pm 415.1$ & $3394.5 \pm 469.1$ & $0.308^{\mathrm{b}}$ \\
\hline
\end{tabular}

Independent samples t-test. ${ }^{\mathrm{a}} \mathrm{P}<0.05$, the difference of fasting blood glucose between control group and GDM group is statistically significant. ${ }^{b} \mathrm{P}>0.05$, the differences are not statistically significant. GDM, gestational diabetes mellitus.

PCR primer sequences were as follows: SHBG mRNA forward primer, 5'-CCTCACCAAGATCACAAAAA-3' and reverse primer, 5'-TCTCGAAGTCCCAGCATAAACC-3', giving a fragment length of $120 \mathrm{bp} ; \beta$-actin forward primer, 5'-AGCACAATGAAGATCAAGATCAT-3' and reverse primer, 5'-ACTCGTCATACTCCTGCTTGC-3', giving a fragment length of $127 \mathrm{bp}$ (Invitrogen Life Technologis). Real-time PCR amplification was carried out in 7500 fast thermocycler (Life Technologies) as follows: $10 \mu \mathrm{l}$ SYBR Premix Ex Taq, $6 \mu 1$ RNase Free $\mathrm{dH}_{2} \mathrm{O}, 1 \mu \mathrm{l}$ each of SHBG and $\beta$-actin forward and reverse primers $(10 \mu \mathrm{M}), 2 \mu \mathrm{l}$ cDNA template. Conditions were: $95^{\circ} \mathrm{C}$ for $5 \mathrm{~min}\left(95^{\circ} \mathrm{C}\right.$ for $10 \mathrm{sec}, 60^{\circ} \mathrm{C}$ for $\left.30 \mathrm{sec}\right) 40$ (no. RR820A;

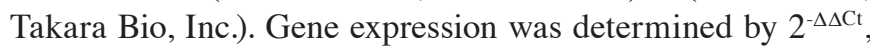
where $\Delta \mathrm{Ct}=\left(\mathrm{Ct}_{\mathrm{SHBG}}-\mathrm{Ct}_{\mathrm{GAPDH}}\right)$ and $\mathrm{Ct}$ is the threshold cycle.

Transfected HTR8-SVneo cell SHBG detection by western blot analysis. Expression of SHBG was tested and analyzed in different transfected groups with the same approach as placental tissue.

Statistical analysis. The direct counting method for $\%$ calculation of the gene frequency. The differences with alleles and genotypes distribution compared with Chi-square statistics, $\mathrm{P}<0.05$ was considered statistically significant. Hardy-Weinberg balance check (HWE) the reliability of the survey data (gene frequency, estimation accuracy and reliability) and disease risk with rs6259 through the SHEsis software (http://analysis.bio-X.cn/myAnalysis.php) (23). The correlation between SHBG levels and genotypes were evaluated by Pearson's correlation coefficient. Logistic regression models were used to analyse the correlation of genotype and disease with odds ratios (ORs) and $95 \%$ confidence intervals (95\% CIs). T-test and LSD t-test were used with $\alpha=0.05$ considered to be significant. All analyses used SPSS 13.0 software (SPSS, Inc., Chicago, IL, USA).

\section{Results}

Clinical data analyses. The statistics and analysis of population characteristics are depicted in Table I, with the 

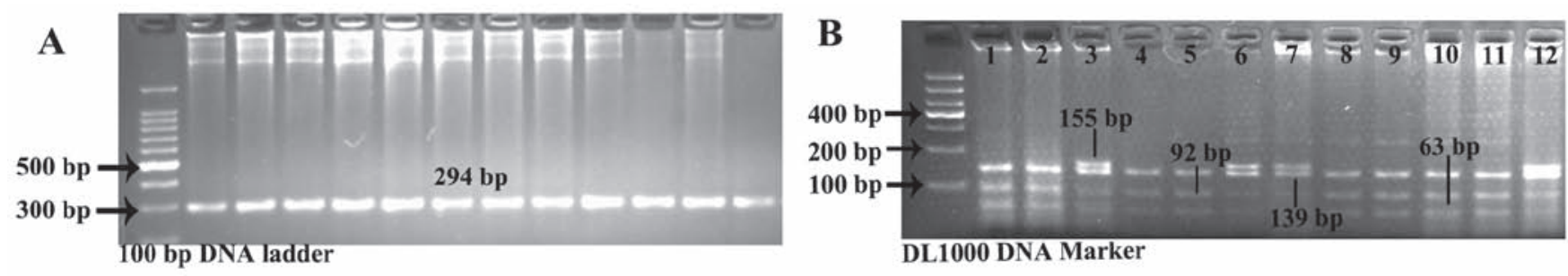

Figure 1. (A) Sex hormone-binding globulin (SHBG) rs6259 fragment amplification by polymerase chain reaction-restriction fragment length polymorphism (PCR-RFLP). PCR fragments, 294 bp. (B) Results after restriction enzyme digestion. The GG genotype was constituted by segments of 139,92 and $63 \mathrm{bp}$, while the AA genotype was characterized by segments of 155 and $139 \mathrm{bp}$ and the GA genotype was characterized by segments of $155,139,92$ and 63 bp. Lanes 1, 2, 4, 5, 8, 9, 10, 11: GG homozygote (Asp/Asp); lanes 3, 6, 12: GA heterozygote (Asn/Asp); lane 7, AA homozygote (Asn/Asn).
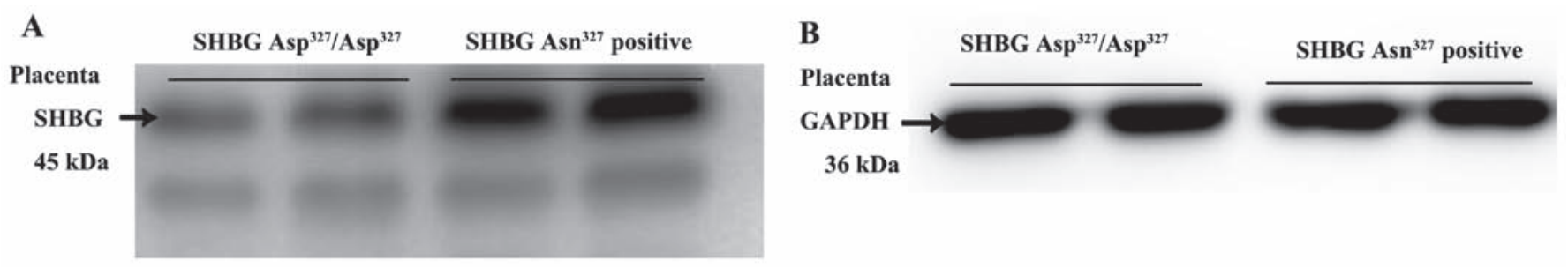

Figure 2. (A) Placenta tissue sex hormone-binding globulin (SHBG) protein expression in different genotype groups by western blot analysis. (B) Placenta tissue GAPDH protein expression in different genotype groups by western blot analysis.

mean \pm standard deviation. The differences of age distribution, gestational weeks, childbearing history and birth weight had no significant difference, but statistically significant difference wasfound in fasting blood glucose between normal and GDM pregnant womean $(\mathrm{P}<0.05)$.

Placenta SHBG gene rs6259 allele frequencies and genotype distribution. PCR fragment amplification is shown in Fig. 1A. Three genotypes were detected in two groups: the GG genotype represented three segments, while the AA genotype was characterized by two parts and GA genotype was constituted by four segments (Fig. 1B). SHEsis online software detected the Hardy-Weinberg balance, control group: $\chi^{2}=0.469, \mathrm{P}=0.493$; GDM group: $\chi^{2}=0.141, \mathrm{P}=0.707$. The gene frequency conforms to the laws of genetic balance constantly $(\mathrm{P}>0.05)$. Allelic frequencies and genotype distributions are given in Table II. Because of the low proportion of AA homozygotes, they were considered together with the GA heterozygotes. In the GDM pregnancy group, $14.17 \%$ had the variant gene, higher than the control group. Compared with the control group, the decreased tendencies were observed in the GDM group with AA and GA group. The result [odd ratio $<1,95 \% \mathrm{CI}=(0-1)$ ] shows that $\mathrm{rs} 6259$ is a protective factor for decreased risk of GDM $(\mathrm{P}=0.043)$. Pearson's $p=0.707$ confirms that rs6259 is highly correlated with the morbidity of GDM.

SHBG expression of different genotypes in placental tissues. Following the results of PCR-RFLP and enzyme digestion, the placental tissues were divided into two groups. As shown in Fig. 2, the SHBG concentration of the GA heterozygote and AA homozygote (SHBG $\mathrm{Asn}^{327}$ positive group) are significantly higher than the GG homozygote (SHBG Asp ${ }^{327} / \mathrm{Asp}^{327}$ group). The difference between the two groups was statistically significant $(\mathrm{t}=2.176, \mathrm{P}=0.035<0.001)$.
Table II. Allele and genotypic frequencies of SHBG Asp ${ }^{327}$ Asn polymorphism in placenta.

\begin{tabular}{lrrrrrr}
\hline & $\begin{array}{c}\text { Control group } \\
(\mathrm{n}=210)\end{array}$ & & \multicolumn{2}{c}{$\begin{array}{c}\text { GDM group } \\
(\mathrm{n}=180)\end{array}$} & \\
\cline { 2 - 3 } Frequencies & $\mathrm{n}$ & $(\%)$ & $\mathrm{n}$ & $(\%)$ & P-value \\
\hline Allele & 86 & 20.48 & 51 & 14.17 & \\
A (Asn) & 334 & 79.52 & 309 & 85.83 & $0.021^{\mathrm{a}}$ \\
G (Asp) & & & & & \\
Genotype & & & & & & \\
GG (Asp/Asp) & 131 & 62.38 & 132 & 73.33 & $0.021^{\mathrm{b}}$ \\
GA+AA & 79 & 37.62 & & 48 & 26.67 & $0.021^{\mathrm{c}}$ \\
GA (Asp/Asn) & 72 & 34.29 & 45 & 25 & $0.046^{\mathrm{d}}$ \\
AA (Asn/Asn) & 7 & 3.33 & 3 & 1.67 & $0.299^{\mathrm{e}}$ \\
\hline
\end{tabular}

Chi-square test, $\mathrm{P}<0.05$, the differences is statistically significant. ${ }^{a}$ The difference of allele frequency between control group and GDM

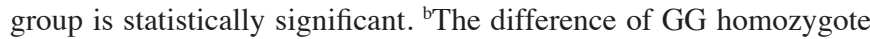
distribution between control group and GDM group is statistically

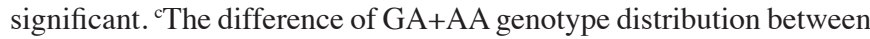
control group and GDM group is statistically significant. SHBG, sex hormone-binding globulin; GDM, gestational diabetes mellitus.

HTR8-SVneo cell transfection. HTR8-SVneo cells were incubated in $5 \% \mathrm{CO}_{2}, 37^{\circ} \mathrm{C}$ incubator. After repeated exploration the optimal transfection conditions were: $\mathrm{MOI}=80,5 \mu \mathrm{g} /$ ml polybrene, which were successfully transfected with recombinant lentivirus and upregulation of SHBG expression (Fig. 3).

Recombinant intracellular SHBG protein assay. Western blot analysis and gel image software analysis demonstrated that the 
$\mathbf{A}$

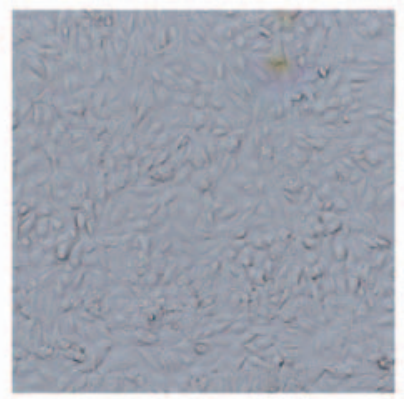

D

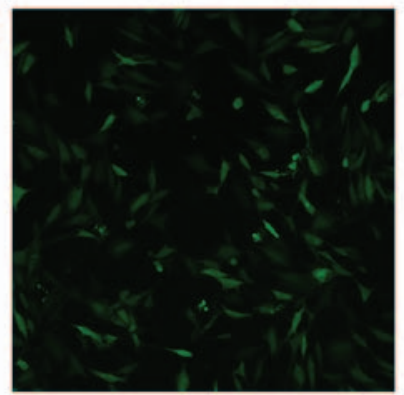

B

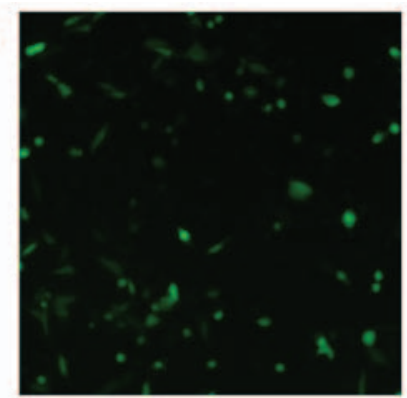

$\mathbf{E}$

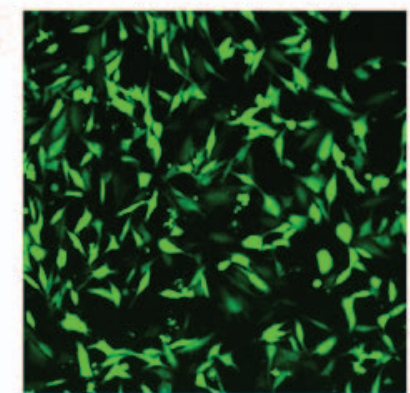

C

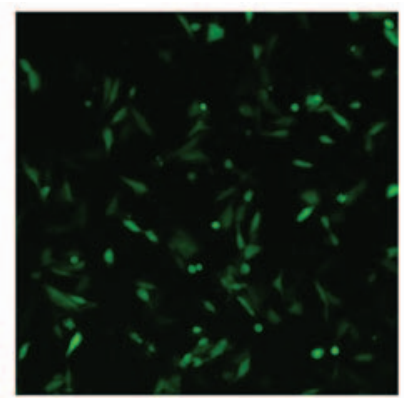

F

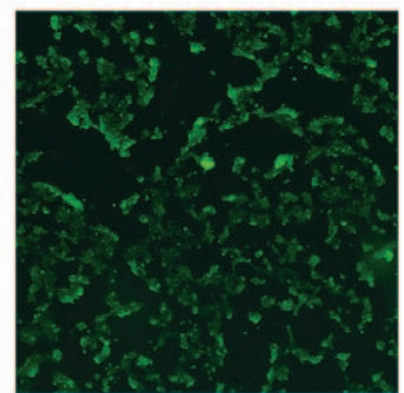

Figure 3. (A) Normal placenta villus trophoblast cells HTR8-SVneo. (B) HTR8-SVneo cells transfected with recombinant lentivirus 96 h (MOI=20, $5 \mu \mathrm{g} / \mathrm{ml}$ polybrene). (C) $\mathrm{MOI}=40,5 \mu \mathrm{g} / \mathrm{ml}$ polybrene. (D) $\mathrm{MOI}=60,5 \mu \mathrm{g} / \mathrm{ml}$ polybrene. (E) $\mathrm{MOI}=80,5 \mu \mathrm{g} / \mathrm{ml}$ polybrene. (F) $\mathrm{MOI}=100$.

Table III. The result of SHBG protein and mRNA in different groups of transfected cells.

A, Analysis of SHBG protein and GAPDH gray ratio in different transfected HTR8-SVneo cells

\begin{tabular}{llcc}
\hline LSD t-test & \multicolumn{1}{c}{ Groups } & P-value & $95 \%$ CI \\
\hline NG & LV-5 & $0.950^{\mathrm{a}}$ & $-0.225-0.240$ \\
& rs6259 Asp & $0.003^{\mathrm{b}}$ & $0.116-0.560$ \\
& rs6259 Asn & $0.000^{\mathrm{c}}$ & $0.463-0.907$ \\
rs6259 Asn & rs6259 Asp & $0.000^{\mathrm{d}}$ & $0.148-0.545$ \\
LV-5 group & rs6259 Asp & $0.002^{\mathrm{e}}$ & $0.136-0.557$ \\
& rs6259 Asn & $0.000^{\mathrm{f}}$ & $0.482-0.902$ \\
\hline
\end{tabular}

B, Analysis of SHBG mRNA transcription in different transfected HTR8-SVneo cells

\begin{tabular}{llcc}
\hline LSD t-test & Groups & P-value & $95 \%$ CI \\
\hline NG & LV-5 & $0.201^{\mathrm{a}}$ & $-0.413-1.890$ \\
& rs6259 Asp & $0.017^{\mathrm{b}}$ & $0.272-2.575$ \\
& rs6259 Asn & $0.000^{\mathrm{c}}$ & $5.660-7.964$ \\
rs6259 Asn & rs6259 Asp & $0.000^{\mathrm{d}}$ & $4.237-6.541$ \\
LV-5 group & rs6259 Asp & $0.001^{\mathrm{e}}$ & $1.011-3.314$ \\
& rs6259 Asn & $0.000^{\mathrm{f}}$ & $6.399-8.703$ \\
\hline
\end{tabular}

LSD t-test, $\mathrm{P}<0.05$, the differences have statistically significant. SHBG, sex hormone-binding globulin; CI, confidence interval.

positive transfection groups showed an increased SHBG level over negative control groups $(\mathrm{t}=2.675, \mathrm{P}=0.011<0.001)$, blank control and normal groups $(\mathrm{P}<0.001)$. There was no significant difference between the blank control group and the normal group (Table IIIA; Figs. 4 and 5).

Detection the SHBG mRNA in transfected HTR8-SVneo cells. According to the LDS-t analysis there were no significant differences between the blank control group and normal cell group ( $\mathrm{P}>0.05)$, in the positive transfection groups a higher average $2^{-\Delta \Delta \mathrm{Ct}}$ for SHBG mRNA were found than the negative control groups $(\mathrm{P}<0.001)$, blank control groups $(\mathrm{P}<0.001)$ and normal cell groups $(\mathrm{P}<0.001)$, the differences were statistically significant (Table IIIB; Fig. 5).

\section{Discussion}

The gene encoding human SHBG is located on chromosome 17p12-13 and is composed of 8 exons and 7 introns (Gene ID, 6462). The length of SHBG gene is $3.2 \mathrm{~kb}$ and it encodes a polypeptide of 402 amino acids. Human SHBG gene is prone to gene mutation, deletion and recombination. Because of its fragility and volatility, it is more likely to accept foreign interference $(24,25)$. The polymorphic and the protein level changes may lead to special expression in certain diseases (26), such as IR damage $(7,27)$, DM $(7,23)$, polycystic ovary syndrome (21), osteoporosis (28), hirsutism (11), and even some hormone-dependent tumors, such as breast $(16,20)$, ovarian (17), endometrial (18) and prostate cancers $(29,30)$. rs6259 is one of the functional SHBG SNPs, which leads to an amino acid substitution of asparagine for aspartic acid at locus 327 (Asp ${ }^{327} \mathrm{Asn}, \mathrm{D} 327 \mathrm{~N}$ ) in the SHBG polypeptide (11).

In our study, 180 pregnant women with GDM and 210 healthy pregnant women were chosen as participants in the program at the same period. The distributions of the genotypes and the allele frequencies had obvious differences in two groups. In GDM group, the frequency of the mutation gene and genotypes 


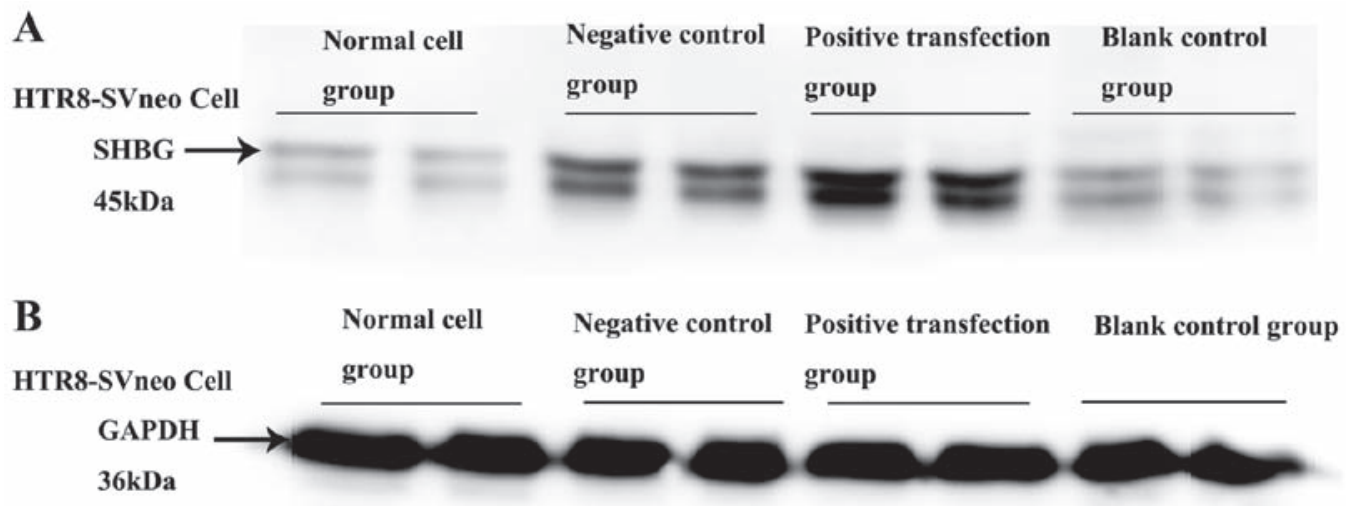

Figure 4. (A) Expression of sex hormone-binding globulin (SHBG) in each group of HTR8-SVneo cells. (B) Expression of GAPDH in each group of HTR8-SVneo cells.
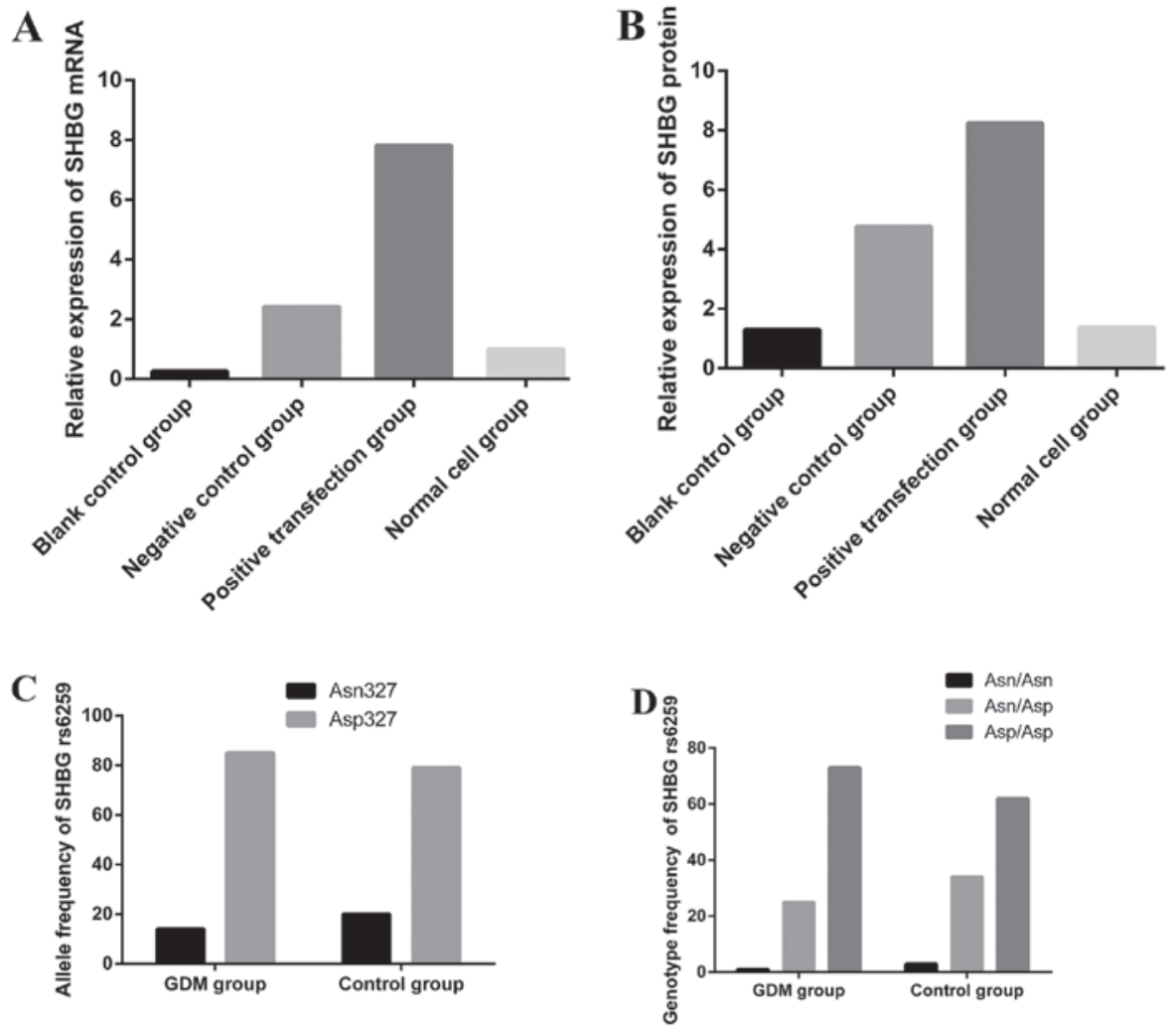

Figure 5. (A) The relative expression of sex hormone-binding globulin (SHBG) mRNA ( $2^{-\Delta \Delta C t}$ ), the positive transfection group led to an obviously higher tendency than the negative control group, the normal group and the blank control group. (B) The relative expression of SHBG (ratio of gray value of SHBG and GAPDH), the positive transfection group was obviously higher than negative control group, the normal group and the blank control group. (C) Distribution of SHBG rs6259 alleles (Asn and Asp) between gestational diabetes mellitus (GDM) and control group. (D) Frequency differences between GDM and control group.

showed decreasing trends. The frequency of the variant allele A is higher in healthy pregnant women of northeast China than in healthy Caucasian and African Americans, confirming the racial diversity in the distribution of this mutation.

Then, we measured SHBG level in each group. We discovered the differences between the two groups with disparate alleles $\left(\mathrm{Asp}^{327}\right.$ or $\left.\mathrm{Asn}^{327}\right)$. Through many repeats, we determined that the variant allele $\mathrm{Asn}^{327}$ have a strong connection with the added tendency of SHBG in the placenta organ. So, considering the result of genotypes screen, we speculated that $\mathrm{Asn}^{327}$ may lead to a reduced risk of GDM.
To clarify the mechanism involved, placental villi trophoblastic cells were cultivated continuously in vitro. With repeatedly recombinant lentivirus transfection, we found that both SHBG protein and SHBG mRNA in transfected HTR8-SVneo cells carried the mutant allele leading to higher level than others without mutation. Excluding other possible interference factors, the strong correlation between SHBG rs6259 variant allele A and SHBG transcription and translation was confirmed. It may be a genetic molecular basis of the pathogenesis of GDM.

It is well-known that type 2 diabetes is an endocrine disease with obvious genetic predisposition. If one of the parents has 
type 2 diabetes, genetic odds of the offspring is between $1 / 7$ and $1 / 13$, but if both parents are affected, the genetic probability is increased to $1 / 2$. Our preliminary experiment assessed the relevance between placental SHBG and GDM (8-10). The placenta has the same genetic material as the fetus, therefore, we anticipate to make a preliminary prediction for the possibility that the next generation achieve insulin resistance and type 2 diabetes, by testing the SHBG level and SHBG rs6259.

In conclusion, the findings of the present study support the result that SHBG SNP rs6259 is closely associated with placental SHBG levels. The mutant $\mathrm{Asn}^{327}$ allele may affect the transcription of SHBG mRNA and activity of the SHBG protein by some mechanisms. Associated with the SHBG rs6259 variant allele A, SHBG protein levels improved in placenta, the risk and progress of GDM may be delayed. SHBG rs6259 and SHBG are protective factors in pathogenesis of GDM, and may possiby be used to deduce the risk of offspring suffering from diabetes in the future.

\section{Acknowledgements}

Not applicable.

\section{Funding}

This study was supported by the National Natural Science Foundation of China (nos. 81300511 and 81170591).

\section{Availability of data and material}

The datasets used and/or analyzed during the current study are available from the corresponding author on reasonable request.

\section{Authors' contributions}

$\mathrm{XZ}$ contributed to manuscript writing, data collection and data analysis. LS contributed to data collection and financial support. ZJ contributed to project development.

\section{Ethics approval and consent to participate}

This study was in accordance with the ethical standards of the Shengjing Hospital of China Medical University and the ethical standards of the 1964 Helsinki declaration and its later amendments. All individual participants included in the study provided informed consents.

\section{Consent for publication}

Not applicable.

\section{Competing interests}

The authors declare that they have no competing interests.

\section{References}

1. Yang HX: Further enhance the research level of gestational diabetes. Chin J Perinat Med 8: 289-291, 2005.

2. Lewis JG, Shand BI, Elder PA and Scott RS: Plasma sex hormone-binding globulin rather than corticosteroid-binding globulin is a marker of insulin resistance in obese adult males. Diabetes Obes Metab 6: 259-263, 2004
3. Sokup A, Szymański M and Góralczyk K: Impaired fasting glucose as a marker of heterogeneity of gestational diabetes mellitus. A study of 1025 women living in the region of Kuyavia and Pomerania in Poland. Endokrynol Pol 60: 348-352, 2009.

4. Buchanan TA, Xiang A, Kjos SL, Lee WP, Trigo E, Nader I, Bergner EA, Palmer JP and Peters RK: Gestational diabetes: antepartum characteristics that predict postpartum glucose intolerance and type 2 diabetes in Latino women. Diabetes 47: 1302-1310, 1998.

5. Morrison JA, Glueck CJ, Daniels S, Wang P and Stroop D: Adolescent oligomenorrhea in a biracial schoolgirl cohort: a simple clinical parameter predicting impaired fasting glucose plus type 2 diabetes mellitus, insulin, glucose, insulin resistance, and centripetal obesity from age 19 to 25 years. Metabolism 60: 1285-1293, 2011.

6. Nanda S, Savvidou M, Syngelaki A, Akolekar R and Nicolaides KH: Prediction of gestational diabetes mellitus by maternal factors and biomarkers at 11 to 13 weeks. Prenat Diagn 31: 135-141, 2011.

7. Perry JR, Weedon MN, Langenberg C, Jackson AU, Lyssenko V, Sparsø T, Thorleifsson G, Grallert H, Ferrucci L, Maggio M, et al; MAGIC: Genetic evidence that raised sex hormone binding globulin (SHBG) levels reduce the risk of type 2 diabetes. Hum Mol Genet 19: 535-544, 2010.

8. Jin Z, Guan X, Gao H, Shang L, Gao M, Su D and Li W: The change in sex hormone binding globulin and the influence by gestational diabetes mellitus in fetal period. Gynecol Endocrinol 25: 647-652, 2009.

9. Sun L, Jin Z, Teng W, Chi X, Zhang Y, Ai W and Wang P: Expression changes of sex hormone binding globulin in GDM placental tissues. J Perinat Med 40: 129-135, 2011.

10. Sun L, Jin Z, Teng W, Chi X, Zhang Y, Ai W and Wang P: SHBG in GDM maternal serum, placental tissues and umbilical cord serum expression changes and its significance. Diabetes Res Clin Pract 99: 168-173, 2013.

11. Cousin P, Calemard-Michel L, Lejeune H, Raverot G, Yessaad N, Emptoz-Bonneton A, Morel Y and Pugeat M: Influence of SHBG gene pentanucleotide TAAAA repeat and $\mathrm{D} 327 \mathrm{~N}$ polymorphism on serum sex hormone-binding globulin concentration in hirsute women. J Clin Endocrinol Metab 89: 917-924, 2004.

12. Power SG, Bocchinfuso WP, Pallesen M, Warmels-Rodenhiser S, Van Baelen H and Hammond GL: Molecular analyses of a human sex hormone-binding globulin variant: evidence for an additional carbohydrate chain. J Clin Endocrinol Metab 75: 1066-1070, 1992

13. Haiman CA, Riley SE, Freedman ML, Setiawan VW, Conti DV and Le Marchand L: Common genetic variation in the sex steroid hormone-binding globulin (SHBG) gene and circulating SHBG levels among postmenopausal women: The Multiethnic Cohort. J Clin Endocrinol Metab 90: 2198-2204, 2005.

14. Cousin P, Déchaud H, Grenot C, Lejeune H, Hammond GL and Pugeat M: Influence of glycosylation on the clearance of recombinant human sex hormone-binding globulin from rabbit blood. J Steroid Biochem Mol Biol 70: 115-121, 1999.

15. Ding EL, Song Y, Manson JE, Hunter DJ, Lee CC, Rifai N, Buring JE, Gaziano JM and Liu S: Sex hormone-binding globulin and risk of type 2 diabetes in women and men. N Engl J Med 361: 1152-1163, 2009.

16. Försti A, Jin Q, Grzybowska E, Söderberg M, Zientek H, Sieminska M, Rogozinska-Szczepka J, Chmielik E, Utracka-Hutka B and Hemminki K: Sex hormone-binding globulin polymorphisms in familial and sporadic breast cancer. Carcinogenesis 23: 1315-1320, 2002.

17. Garcia-Closas M, Brinton LA, Lissowska J, Richesson D, Sherman ME, Szeszenia-Dabrowska N, Peplonska B, Welch R, Yeager M, Zatonski W, et al: Ovarian cancer risk and common variation in the sex hormone-binding globulin gene: a population-based case-control study. BMC Cancer 7: 60, 2007.

18. Kataoka N, Cai Q, Xu WH, Xiang YB, Cai H, Zheng W and Shu XO: Association of endometrial cancer risk with a functional polymorphism $\left(A s p^{327} A s n\right)$ in the sex hormone-binding globulin gene. Cancer 109: 1296-1302, 2007.

19. Eriksson AL, Lorentzon M, Mellström D, Vandenput L, Swanson C, Andersson N, Hammond GL, Jakobsson J, Rane A, Orwoll ES, et al: SHBG gene promoter polymorphisms in men are associated with serum sex hormone-binding globulin, androgen and androgen metabolite levels, and hip bone mineral density. J Clin Endocrinol Metab 91: 5029-5037, 2006. 
20. Cui Y, Shu XO, Cai Q, Jin F, Cheng JR, Cai H, Gao YT and Zheng W: Association of breast cancer risk with a common functional polymorphism (Asp327Asn) in the sex hormone-binding globulin gene. Cancer Epidemiol Biomarkers Prev 14: 1096-1101, 2005.

21. Bendlová B,Zavadilová J, Vanková M, Vejrazková D, Lukásová P, Vcelák J, Hill M, Cibula D, Vondra K, Stárka L, et al: Role of D327N sex hormone-binding globulin gene polymorphism in the pathogenesis of polycystic ovary syndrome. J Steroid Biochem Mol Biol 104: 68-74, 2007.

22. American Diabetes Association: Diagnosis and classification of diabetes mellitus. Diabetes Care 36 (Suppl 1): S67-S74, 2013.

23. Shi YY and He L: SHEsis, a powerful software platform for analyses of linkage disequilibrium, haplotype construction, and genetic association at polymorphism loci. Cell Res 15: 97-98, 2005

24. Cousin P, Billotte J, Chaubert P and Shaw P: Physical map of $17 \mathrm{p} 13$ and the genes adjacent to p53. Genomics 63: 60-68, 2000

25. Toscano V, Balducci R, Bianchi P, Guglielmi R, Mangiantini A and Sciarra F: Steroidal and non-steroidal factors in plasma sex hormone binding globulin regulation. J Steroid Biochem Mol Biol 43: 431-437, 1992.
26. Xita $\mathrm{N}$ and Tsatsoulis A: Genetic variants of sex hormone-binding globulin and their biological consequences. Mol Cell Endocrinol 316: 60-65, 2010.

27. Pinós T, Barbosa-Desongles A, Hurtado A, SantamariaMartínez A, de Torres I, Morote J, Reventós J and Munell F: Identification, characterization and expression of novel sex hormone binding globulin alternative first exons in the human prostate. BMC Mol Biol 10: 59, 2009.

28. Goderie-Plomp HW, van der Klift M, de Ronde W, Hofman A, de Jong FH and Pols HA: Endogenous sex hormones, sex hormone-binding globulin, and the risk of incident vertebral fractures in elderly men and women: The Rotterdam Study. J Clin Endocrinol Metab 89: 3261-3269, 2004.

29. Selva DM and Hammond GL: Human sex hormone-binding globulin is expressed in testicular germ cells and not in sertoli cells. Horm Metab Res 38: 230-235, 2006.

30. Weiss JM, Huang WY, Rinaldi S, Fears TR, Chatterjee N, Hsing AW, Crawford ED, Andriole GL, Kaaks R and Hayes RB: Endogenous sex hormones and the risk of prostate cancer: a prospective study. Int J Cancer 122: 2345-2350, 2008. 